\title{
Green Dyeing of Silk Fabric with Turmeric Powder Using Tamarind Seed Coat as Mordant
}

\author{
Priti Sarker, A. K. M. Ayatullah Hosne Asif* (i), Mahbubur Rahman, Md. Mujahidul Islam, \\ Khan Hridom Rahman
}

Department of Textile Engineering, Mawlana Bhashani Science and Technology University, Santosh, Tangail, Bangladesh

Email: *asif.ustc2018@outlook.com

How to cite this paper: Sarker, P., Ayatullah Hosne Asif, A.K.M., Rahman, M., Mujahidul Islam, Md. and Rahman, K.H. (2020) Green Dyeing of Silk Fabric with Turmeric Powder Using Tamarind Seed Coat as Mordant. Journal of Materials Science and Chemical Engineering, 8, 65-80. https://doi.org/10.4236/msce.2020.82007

Received: January 2, 2020

Accepted: February 23, 2020

Published: February 26, 2020

Copyright $\odot 2020$ by author(s) and Scientific Research Publishing Inc. This work is licensed under the Creative Commons Attribution International License (CC BY 4.0).

http://creativecommons.org/licenses/by/4.0/

(c) (i) Open Access

\begin{abstract}
The current study is aimed to explore the sustainable dyeing approach of silk fabric with turmeric powder using tannin as mordant extracted from tamarind seed coat. For that, tamarind seed coat tannin was extracted and applied as natural mordant alone and in combination with metal mordant namely copper sulphate for dyeing silk fabric with the extract of turmeric powder. Dyeing parameters such as temperature, time and mordant concentration were varying for optimizing the process. The color strength, color coordinates, color fastness to wash, perspiration, water and rubbing were evaluated for examining dyeing performance. Firstly, tannin was extracted from tamarind seed coat and applying on the silk fabric at $95^{\circ} \mathrm{C}$ temperature for $45 \mathrm{~min}$ by varying concentration. Among them $15 \mathrm{~g} / \mathrm{l}$ shows better results. Some samples were mordanted with both $15 \mathrm{~g} / \mathrm{l}$ extracted tannin and $0.5 \%$ copper sulphate solution. The mordanted samples were dyed with turmeric dye by varying the time and temperature. By analyzing the test results, the sample mordanted with extracted tannin showed high color strength and good fastness properties dyeing at $80^{\circ} \mathrm{C}$ for $60 \mathrm{~min}$. The application of $0.5 \%$ copper sulphate mordant enhanced sustainable wash fastness properties.
\end{abstract}

\section{Keywords}

Tamarind Seed Powder, Tannin, Natural Mordant, Turmeric Powder, Silk

\section{Introduction}

Tannin is one in every necessary natural mordant commonly called bean tree which is one in every foremost necessary utile tree species within the Indian sub-continent [1] [2]. Coloration of textiles with natural mordant associated graded dyes was a recent specialty of history. As we are living in the modern age 
of science and technology, trendy science and technology are developing day by day all-together with several advancements in textile innovations [3] [4]. The art of coloration was considered as early as of analysis [5] [6]. Throughout archeological excavations, numerous leftover unreal textiles throughout the planet provide confirmation to the act of coloring in ancient human civilizations [7]. From prehistoric time until the nineteenth century, natural dyes were used simply to textile coloration. Tamarind (Tamarindus indica L.) belongs to the family fabaceae (Leguminosae) subfamily Caesalpinioideae and most elements of this tree are found to be of some use [8] [9]. The utilization of fruit pulp has been well-known for awfully very long time. Different uses persist in food, chemicals and prescription drugs [10] [11]. The seed consists of half-hour exhausting however brown seed coat and seventy percent kernel. The kernels are separated from the seed coat either by preparation or by soaking the seeds in water. The poached or roast kernels can be eaten up and generally dried and grounded into flour for creating pan-cakes or mixed with rice. The kernels contain polysaccharides having an awfully sensible size property or utilized as a sizing agent for jute and textile yarns. Tamarind seeds inhibit the expansion of urinary crystals and are utilized in the treatment of patient's continual excretory organ stones [12]. The seed extract is additionally reportable to contain synthetic resin antioxidants and antimicrobial activity [13] [14]. The seed coat containing four-hundred water soluble matter is nothing however a mix of tannins. It is used for wound healing associated degreed as an anti-dysenteric drug. It is additionally used as a staple for the preparation of laminate adhesives [15] [16]. With a specific astringent style, the profile of polyphenolics gift within the tamarind seed coat was found to be dominated by proanthocyanidin, meaning a group of compounds shaped by the condensation or chemical change of flavan-3-ol or flavan-3,4-diol, normally called condensed tannins or phlorotannin [17].

Tannin is an astringent vegetable product found during a wide selection of plant components like bark, wood, fruit, fruit pods, leaves, roots and plant galls [18] [19]. Tannins are outlined as water soluble polyphenolic compounds of high relative molecular mass (about 500 - 3000) containing phenoplast radical teams to modify them to make effective crosslink between proteins and alternative macromolecules. They are primarily utilized in the preservation of animal skin, glues, stains and mordants [20] [21]. Meanwhile, natural fibres like cotton have terribly low affinity for many of the natural dyes. The tannins play a very important role in cotton coloring to retain coloring matter for good [22] [23]. The aim of getting ready the vegetable fibres with tannic acid isn't such a lot to mend the coloring matter, on fix bound gold-bearing salts like copper, iron, etc., within the sort of insoluble tannates [24]. The metal tannates bequest on the fabric forms insoluble lakes with the natural dyes throughout the coloring method and leads to improved fastness properties [25] [26]. Recently, thanks to increasing awareness of environmental problems and conjointly pollution made by artificial dyes, wide unfold interest has emerged within the coloring of textile fibres mistreatment natural colorants on account of their higher biodegradability [27] 
and better compatibility with the atmosphere, comparatively low toxicity, repugnance. However, most analyses on natural dyes had been centered on the elemental aspects of the natural dyes just like the property of coloring, light fastness and wash fastness [28]. Very little attention, here coloring of silk using natural dyes extracted from natural plants wherever the name of natural dyes along with all the dyes derived from Turmeric (Curcumalonga).
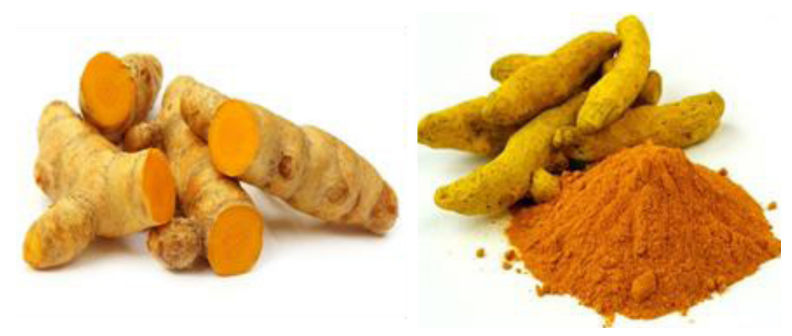

Figure 1. Turmeric and powder form.

Indigenous to the Indian subcontinent and Southeast Asia, it needs temperature between $20^{\circ} \mathrm{C}$ and $30^{\circ} \mathrm{C}$ and significant annual rainfall to thrive. The plants are harvested annually for their roots and propagated from some rhizomes in the next season [29] [30]. If not used fresh, the rhizome is boiled in water for about 30 - 45 minutes, then dried in a hot oven and then ground to a deep orange-yellow powder (Figure 1), which is commonly used as a coloring and flavoring agent. It is used in many Asian cuisines, especially for curry and painting [31].

The findings of this work offer a new area of use for large amounts of seed coating, which are available as residual material during the production of tamarind seed powder, used as a sizing agent and silk dye with saffron powder dyes. Silk is a natural fiber extracted as filaments from silkworms. The most popular type of silk used worldwide is the silkworm collected from Bombyx Mori silkworms. Natural silk is a continuous filament of proteins rotated by silkworms. The spun silk is used in this research work. Although varieties of fabrics are available on the market, silk remains the queen of fabrics.

\section{Experimental Methodology}

In this research work following materials were used throughout:

\subsection{Fabric}

Degummed silk fabric was used in this project work which was collected from Bangladesh Sericulture Research and Training Institute, Rajshahi-6207. The fabric specification is as follows-(Plain weave, 50 EPI, 35 PPI, Warp count-25, Weft count-20, GSM-170).

\subsection{Mordanting Materials}

Tamarind (Tamarindus indica L.) seed coat was used as natural mordant which 
was collected from local market of Tangail Town, Bangladesh. Copper sulphate $\left(\mathrm{CuSO}_{4}\right)$ was used as metallic mordant which was supplied by physical lab, Textile Engineering Department, MBSTU, Tangail, Bangladesh.

\subsection{Colorants}

Turmeric powder was used as natural colorants which were extracted from turmeric collected from local market of Tangail Town.

\subsection{Separation of Tamarind Seed Coat for Extraction of Tannin}

The tamarind seeds were dried in a hot oven at $100^{\circ} \mathrm{C}$ for $30 \mathrm{~min}$. The coat was removed from the seeds by manual crushing and separated and then ground into powder form.

\subsection{Tamarind Seed Husk}

Tamarind seed husk is brown outer shell is obtained after roasting seeds and seed husk constitutes $35 \%$ of tamarind seed weight. Tamarind seed husk contains $20 \%-23 \%$ fibers and high content of polymeric tannins. Tamarind seed husk used as biomass fuel and cattle feed.

\subsection{Tanin Extraction Procedure}

The finely powdered tamarind seed coat ( $200 \mathrm{~g})$ was extracted with water (400 cc) for $2 \mathrm{hr}$ at boil and then cooled. After cooling it was filtered through a fine muslin cloth and the filtrate was collected separately. The remaining residue was extracted three more times, in order to complete the extraction. The total extract $(1600 \mathrm{cc})$ was heated to boil and was allowed to stand overnight and filtered again. The clear filtrate was concentrated using heating mantle. And then sample was treated with saturated brine $\mathrm{NaCl}$ solution. A brownish colored precipitate thus obtained was filtrated and dried in an oven to yield brown colored tamarind seed coat tannin in powder (Figure 2).

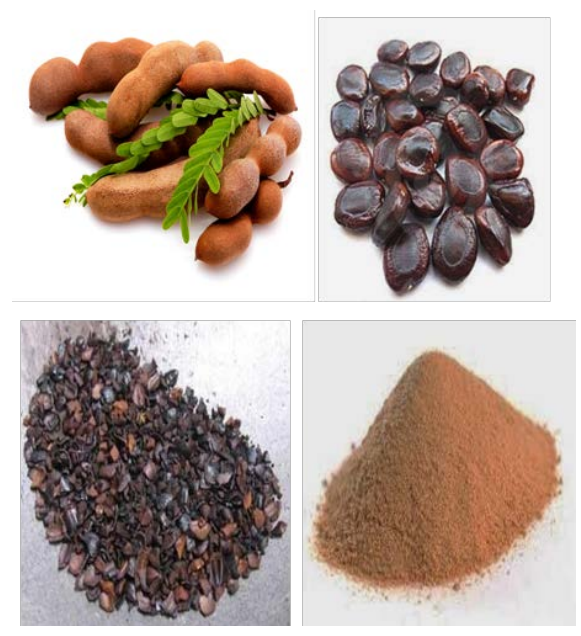

Figure 2. Separation of tamarind seed coat for extraction of tannin. 


\subsection{Extraction of Colorants}

Turmeric colorant was extracted using water as the medium. Two grams of the colorants in the form of fine powder were mixed with $100 \mathrm{ml}$ of water and allowed to soak for $30 \mathrm{~min}$. Then the mixture was boiled for $60 \mathrm{~min}$. The contents were cooled and filtered. The filtrate was used for dyeing.

\subsection{Mordanting}

Pre-mordanting technique was used for this study. For optimizing process, silk fabrics were treated with tamarind seed coat mordant solution using different concentration $(5,10,15,20$ and 25) $\mathrm{g} / \mathrm{l}$ and this treatment was carried out at $95^{\circ} \mathrm{C}$ for $45 \mathrm{~min}$, keeping the liquor to material ratio 20:1. Among the concentration of mordant, we got $15 \mathrm{~g} / \mathrm{l}$ as optimum concentration. The silk fabrics mordanted with $15 \mathrm{~g} / \mathrm{l}$ tamarind seed coat mordant concentration were further treated with $0.5 \%$ (owf) copper sulphate $\left(\mathrm{CuSO}_{4}\right)$ solution at $85^{\circ} \mathrm{C}$ for $45 \mathrm{~min}$, keeping the liquor to material ratio as 20:1. Silk fabrics, only mordanted with tamarind seed coat mordant and in combination with copper sulphate mordants, were squeezed and subjected to dyeing.

\subsection{Dyeing Method}

Dyeing was carried out in IR Dyer machine, physical lab, Textile Engineering Department, MBSTU, Tangail. For dyeing we kept the liquor to material ratio of 20:1. Pre-mordanted fabrics were introduced into the dyeing solution at room temperature and slowly the temperature was raised. For process optimization, we use different temperature for dyeing $\left(40^{\circ} \mathrm{C}, 60^{\circ} \mathrm{C}, 80^{\circ} \mathrm{C}, 100^{\circ} \mathrm{C}\right)$. And finally $80^{\circ} \mathrm{C}$ was chosen as dyeing temperature. The dyeing was continued at $80^{\circ} \mathrm{C}$ temperature for different times $(40 \mathrm{~min}, 50 \mathrm{~min}, 60 \mathrm{~min}, 70 \mathrm{~min}, 80 \mathrm{~min}, 90$ $\mathrm{min}$ ) and finally got $60 \mathrm{~min}$ as optimum time. After dyeing, the fabrics were rinsed and air-dried in flat dryer machine. Then, the soaping was done for removing unfixed dye from the fabric surface by $0.5 \mathrm{~g} / 1$ ISO standard soap keeping the material: liquor ratio $1: 10$ at $70^{\circ} \mathrm{C}$ for 10 minutes. After soaping the samples were squeezed and air dried.

\subsection{Fastness Measurement}

In this research, the following fastness properties were measured [32] [33] [34] [35].

Color fastness to wash (ISO 105 C04).

Color fastness to water (ISO 105 E01).

Color fastness to rubbing (ISO $105 \mathrm{X12}$ ).

Color fastness to perspiration (ISO 105 E04).

\subsubsection{Color Fastness to Wash (ISO 105 C04)}

This test is carried out to evaluate the colorfastness to washing of textiles which are expected to withstand frequent wash. The fabric color loss and surface changes resulting from detergent solution and abrasive action of five typical 
hand or home launderings, with or without chlorine, are roughly approximated by one 45 min test.

\subsubsection{Color Fastness to Water (ISO 105 E01)}

This test method is designed to measure the resistance to water of dyed, printed, or otherwise colored textile yarns and fabrics. Distilled water or deionized water is used in this test method because natural (tap) water is variable in composition.

\subsubsection{Color Fastness to Rubbing (ISO $105 \mathrm{X12}$ )}

This test method is designed to determine the amount of color transferred from the surface of colored textile materials to other surfaces by rubbing. It is applicable to textiles made from all fibers in the form of yarn or fabric whether dyed, printed or otherwise colored. It is not recommended for use for carpets or for prints where the singling out of areas may be too small using this method. Test procedures employing white test cloth squares, both dry and wet with water, are given. As washing, dry-cleaning, shrinkage, ironing, finishing may affect the degree of color transfer from a material, the test may be made before, after or before and after any such treatment.

\subsubsection{Color Fastness to Perspiration (ISO 105 E04)}

This test method is used to determine the fastness of colored textiles to the effects of acid perspiration. It is applicable to dyed, printed or otherwise colored textile fibers, yarns and fabrics of all kinds and to the testing of dyestuffs as applied to textiles.

\subsection{Color Differences Using CIE L*a*b* Coordinates}

Defined by the Commission Internationale de l'Eclairage (CIE), the $\mathrm{L}^{\star} \mathrm{a}^{\star} \mathrm{b}^{\star}$ color space was modeled after a color-opponent theory stating that two colors cannot be red and green at the same time or yellow and blue at the same time. As shown below, $\mathrm{L}^{*}$ indicates lightness, $\mathrm{a}^{*}$ is the red/green coordinate, and $\mathrm{b}^{*}$ is the yellow/blue coordinate. Deltas for $\mathrm{L}^{\star}\left(\Delta \mathrm{L}^{*}\right), \mathrm{a}^{*}\left(\Delta \mathrm{a}^{*}\right)$ and $\mathrm{b}^{*}\left(\Delta \mathrm{b}^{*}\right)$ may be positive $(+)$ or negative $(-)$. The total difference, Delta $\mathrm{E}\left(\Delta \mathrm{E}^{\star}\right)$, however, is always positive.

$\Delta \mathrm{L}^{\star}\left(\mathrm{L}^{\star}\right.$ sample minus $\mathrm{L}^{\star}$ standard $)=$ difference in lightness and darkness $(+=$ lighter, - = darker)

$\Delta \mathrm{a}^{\star}\left(\mathrm{a}^{\star}\right.$ sample minus $\mathrm{a}^{\star}$ standard $)=$ difference in red and green $(+=$ redder, - = greener)

$\Delta \mathrm{b}^{\star}\left(\mathrm{b}^{\star}\right.$ sample minus $\mathrm{b}^{\star}$ standard $)=$ difference in yellow and blue $(+=$ yellower, - = bluer) [36].

\subsection{Color Differences Using CIE $\mathrm{L}^{*} \mathrm{C} * \mathrm{H}^{*}$ Coordinates}

The $L^{\star} C^{\star} h$ color space is similar to $L^{\star} a^{\star} b^{\star}$, but it describes color differently using cylindrical coordinates instead of rectangular coordinates. In this color space, $L^{*}$ indicates lightness, $C^{*}$ represents chroma, and $\mathrm{h}$ is the hue angle. Chroma and hue are calculated from the $\mathrm{a}^{*}$ and $\mathrm{b}^{\star}$ coordinates in $\mathrm{L}^{*} \mathrm{a}^{\star} \mathrm{b}^{*}$. Deltas 
for lightness $\left(\Delta \mathrm{L}^{\star}\right)$, chroma $\left(\Delta \mathrm{C}^{\star}\right)$, and hue $\left(\Delta \mathrm{H}^{\star}\right)$ may be positive $(+)$ or negative $(-)$. These are expressed as:

$\Delta \mathrm{L}^{*}\left(\mathrm{~L}^{*}\right.$ sample minus $\mathrm{L}^{*}$ standard $)=$ difference in lightness and darkness (+ = lighter, $-=$ darker)

$\Delta C^{\star}\left(C^{\star}\right.$ sample minus $C^{\star}$ standard $)=$ difference in chroma $(+=$ brighter, $-=$ duller)

$\Delta \mathrm{H}^{\star}\left(\mathrm{H}^{\star}\right.$ sample minus $\mathrm{H}^{\star}$ standard $)=$ difference in hue [36].

\section{Results and Discussion}

Silk fabrics were dyed with natural dyes extracted from turmeric in various condition with tamarind seed coat tannin and $0.5 \%$ concentrated Copper sulphate $\left(\mathrm{CuSO}_{4}\right)$ applied as mordanting agents to intensify the natural dye fixation. Influences of mordant concentration variation, time and temperature variation for color strength (CS) of selected samples were also examined. Dyeing performance of the dyed samples were assessed by evaluating several elementary parameters such as Color fastness to wash, Color fastness to rubbing, Color fastness to perspiration (alkaline and acidic) and Color fastness to water.

\subsection{Effect of Tamarind (Mordant) Concentration Variation on K/S Values of the Dyed Fabric}

Figure 3 shows that, K/S value of $15 \mathrm{gm} / 1$ mordant using sample is high than 5 $\mathrm{gm} / \mathrm{l}, 10 \mathrm{gm} / \mathrm{l}$ and $20 \mathrm{gm} / \mathrm{l}$ mordant using sample. Lower values of the samples show that dye has lower substantivity towards the fabrics.

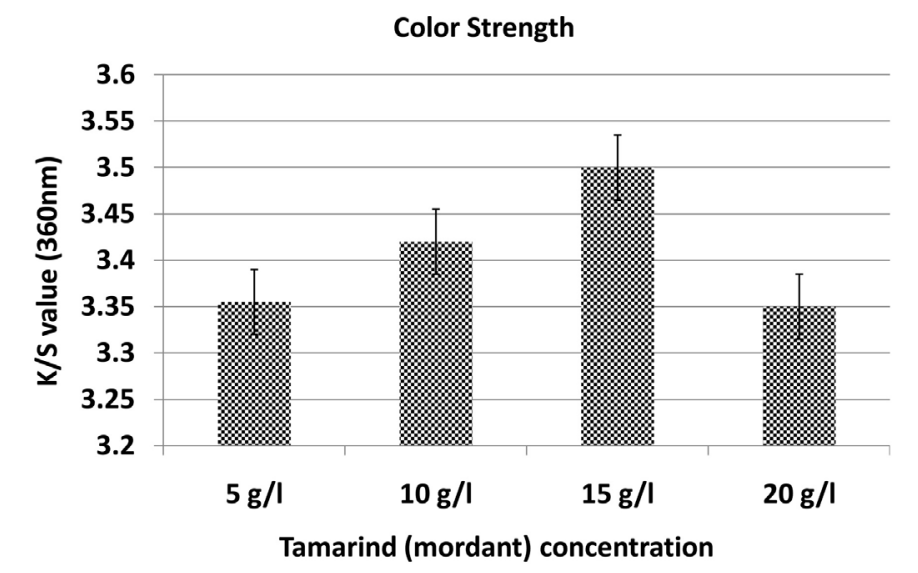

Figure 3. Tamarind (mordant) concentration variation on $\mathrm{K} / \mathrm{S}$ values of the dyed fabric.

\subsection{Effect of Temperature Variation on K/S Values of the Dyed Fabric}

Figure 4 shows that, color strength $(\mathrm{K} / \mathrm{S})$ value of the sample dyed with $80^{\circ} \mathrm{C}$ is high and it is decreasing at the temperature of $60^{\circ} \mathrm{C}, 40^{\circ} \mathrm{C}$, room temperature as well as $100^{\circ} \mathrm{C}$. At $60^{\circ} \mathrm{C}$ and $100^{\circ} \mathrm{C}$ temperature, $\mathrm{K} / \mathrm{S}$ value is moderate. At room temperature $\left(25^{\circ} \mathrm{C}\right)$ and $40^{\circ} \mathrm{C}$ temperature, $\mathrm{K} / \mathrm{S}$ value is low. 


\section{Color Strength}

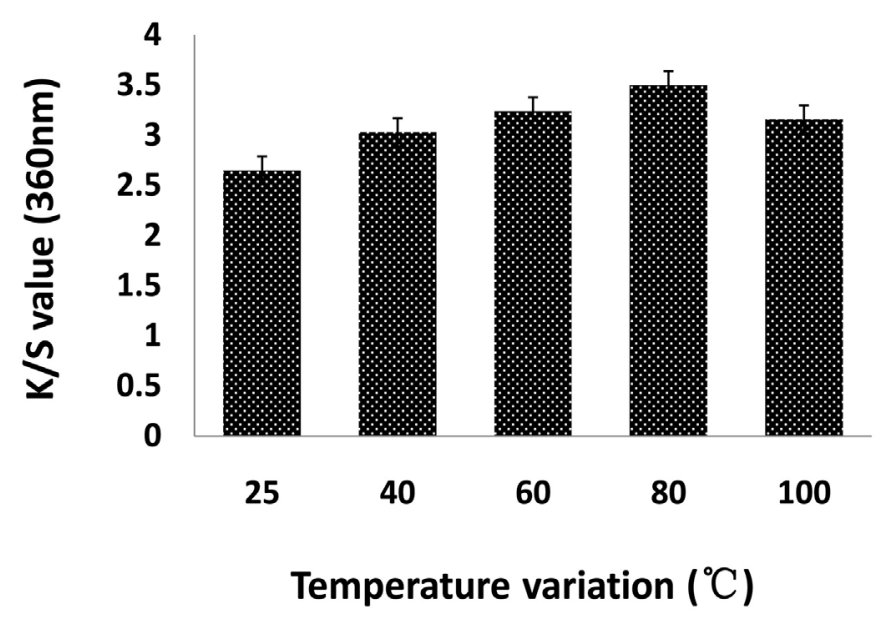

Figure 4. Temperature variation on $\mathrm{K} / \mathrm{S}$ values of the dyed fabric.

\subsection{Effect of Time Variation on $\mathrm{K} / \mathrm{S}$ Values of the Dyed Fabric}

Figure 5 illustrates that, K/S value of $60 \mathrm{~min}$ sample is high, for $80 \mathrm{~min}$ and 90 min sample is moderate; for $15 \mathrm{~min}$ and $40 \mathrm{~min}$ sample is low. Lower values of the samples shows that dye has lower substantivity towards the fabrics.

\section{Color Strength}

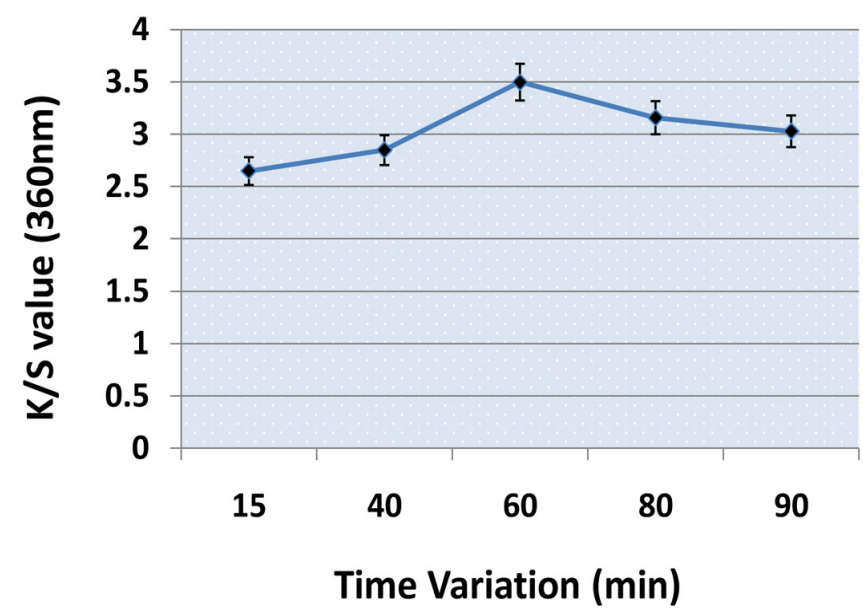

Figure 5. Illustration of time variation on K/S values of the dyed fabric.

\subsection{Effect of Tamarind (Mordant) Concentration Variation on Brightness, Chromacity and Hue}

Figure 6 illustrates that, concentration variation of alum has no significant effect on brightness, chromacity and hue. But brightness result was excellent with 10 gm/l Tamarind (mordant) and with others it was good. And chromacity was moderate for every concentration. With $25 \mathrm{gm} / \mathrm{l}$ tamarind (mordant) hue effect was good than that of other mordants. 


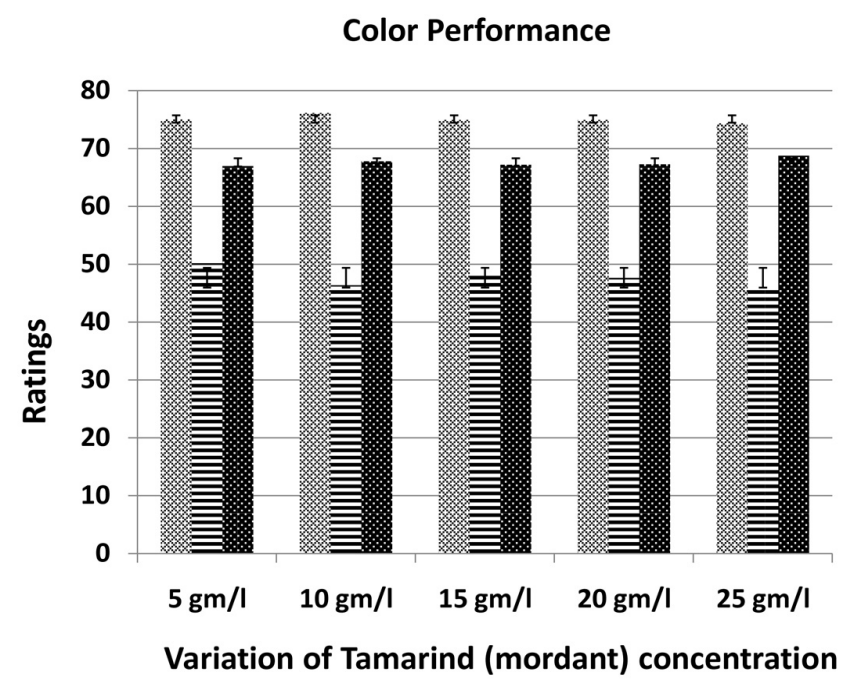

Figure 6. Tamarind (mordant) concentration variation on brightness, chromacity and hue.

\subsection{Effect of Temperature Variation on Brightness, Chroma and Hue}

Figure 7 illustrates that, temperature variation has no significant effect on brightness, chromacity and hue. But brightness result was excellent at room temperature and with others it was moderate to excellent. Chromacity was good to excellent for every temperature. With $100^{\circ} \mathrm{C}$ temperature hue effect was good than that of other temperature.

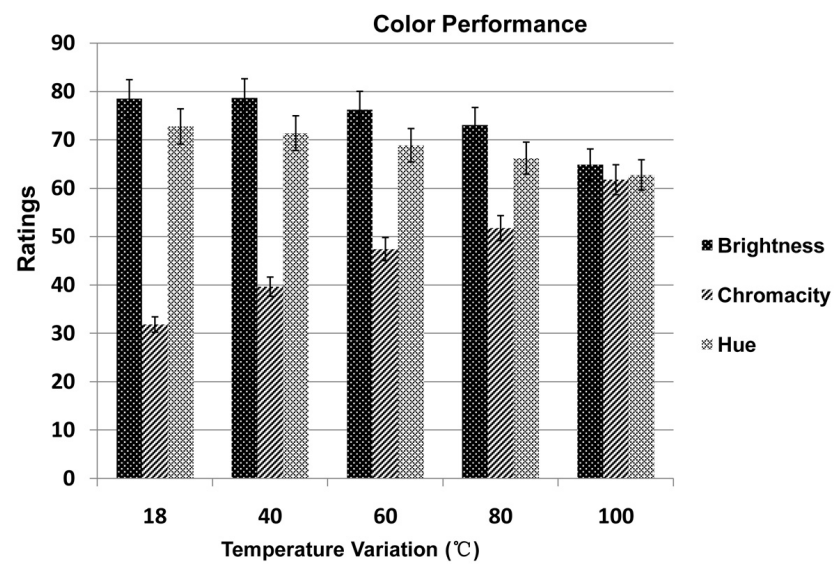

Figure 7. Variation of temperature on brightness, chromacity and hue.

\subsection{Effect of Time Variation on Brightness, Chromacity and Hue}

Figure 8 illustrates that, time variation has no significant effect on brightness, chromacity and hue. But brightness result was excellent at $15 \mathrm{~min}$. and with others it was moderate to excellent and chromacity was good to excellent for every time. With $60 \mathrm{~min}$ hue effect was good than that of other temperature. 


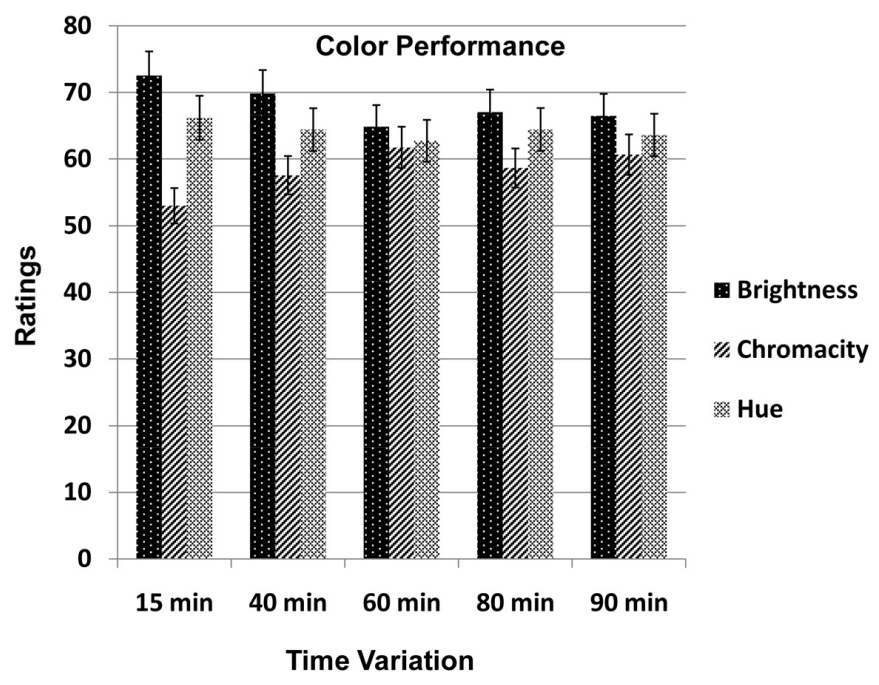

Figure 8. Effect of time variation on brightness, chromacity and hue.

Figure 9 shows the images of different samples at different processing time. After mordanting with tamarind seed coat tannin the sample gains some color. The only dyed sample is very bright but its fastness properties are not as good as previously observed. For regaining the brightness, the sample was further treated with copper sulphate but it has got a little change.
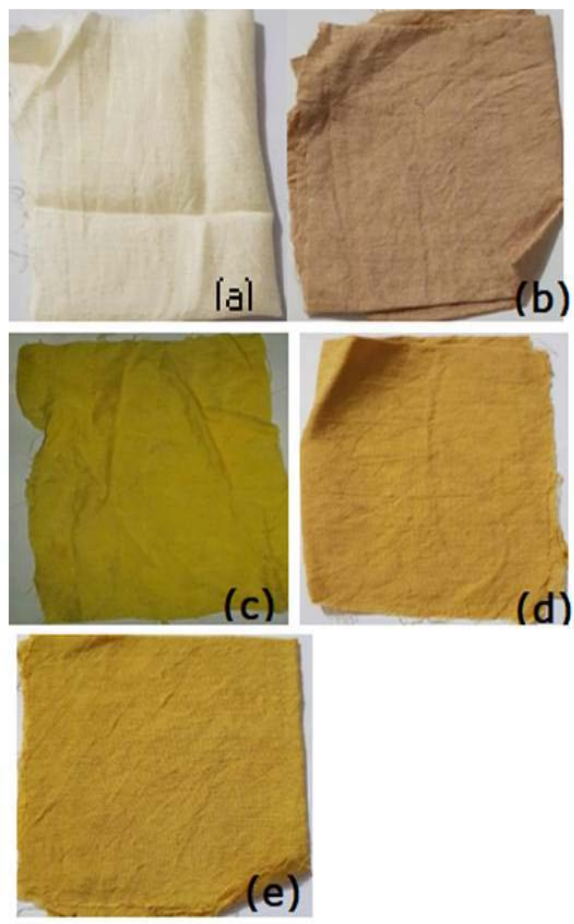

Figure 9. Representation of different dyed samples with different parameters. (a) Raw sample (without mordant); (b) Mordanted sample; (c) Only dyed sample; (d) Mordanted and dyed sample; (e) Mordanted, dyed and $\mathrm{CuSO}_{4}$ treated sample. 


\subsection{Effect of Color Fastness to Wash on Change of Dyeing Parameter}

Color fastness to wash was observed by both change in color and staining in color grey scale. The result is shown in Table 1 .

Table 1. Color fastness to wash at various dyeing parameters.

\begin{tabular}{ccccccccc}
\hline Samples & \multirow{2}{*}{$\begin{array}{c}\text { Change in } \\
\text { color }\end{array}$} & \multicolumn{6}{c}{ Staining in color } \\
\cline { 3 - 8 } & & Diacetate Cotton & Polyamide & Polyester & Acrylic & Wool \\
\hline Only dyed Sample & $2-3$ & 3 & 2 & 2 & 3 & 3 & $2-3$ \\
$\begin{array}{c}\text { Mordanted and dyed } \\
\text { Sample }\end{array}$ & 4 & 4 & 3 & $2-3$ & 5 & 5 & 5 \\
$\begin{array}{c}\text { Mordanted, dyed and } \\
\text { Copper sulphate } \\
\text { treated Sample }\end{array}$ & $4-5$ & $4-5$ & $3-4$ & 3 & 5 & 5 & 5 \\
\hline
\end{tabular}

The above observation implies that, color fastness to wash for only turmeric dyed sample was not good enough (the range between fair to good). Color fastness to wash for mordanted and dyed sample has been improved (it was at the range very good to excellent). And, color fastness to wash for mordanted, dyed and copper sulphate treated sample has been slightly improved than the previous one.

\subsection{Effect of Color Fastness to Rubbing on Different Dyeing Parameter}

Color fastness to rubbing was done by crockmeter and observed by Grey scale for staining in color. The result is shown in Table 2.

Table 2. Color fastness to rubbing on different dyeing parameter.

\begin{tabular}{ccc}
\hline Samples & \multicolumn{2}{c}{ Staining in color } \\
\cline { 2 - 3 } Only dyed Sample & Dry Rub & Wet Rub \\
\hline Mordanted and dyed Sample & 4 & $3-4$ \\
Mordanted, dyed and Copper sulphate treated Sample & 4 & $4-5$ \\
\hline
\end{tabular}

The above observation implies that, color fastness to rubbing (both in dry rub and wet rub) for "only turmeric dyed sample" was improved in case of "tamarind powder mordanted and dyed sample". Color fastness to rubbing for "mordanted, dyed and copper sulphate treated sample" has been almost same to "mordanted and dyed sample".

\subsection{Effect of Color Fastness to Perspiration on Different Dyeing Parameter}

Color fastness to perspiration was observed by both grey scale for change in color and staining in color. The result is shown in Table 3. 
Table 3. Color fastness to perspiration on different dyeing parameter.

\begin{tabular}{cccccccccc}
\hline \multirow{2}{*}{ Samples } & Test Medium & Change & \multicolumn{7}{c}{ Staining in color } \\
\cline { 5 - 10 } & in color & Diacetate & Cotton & Polyamide & Polyester & Acrylic & Wool \\
\hline $\begin{array}{c}\text { Only dyed } \\
\text { Sample }\end{array}$ & Alkaline & $3-4$ & 4 & 4 & 4 & 4 & 4 & 4 \\
$\begin{array}{c}\text { Mordantedand } \\
\text { dyed Sample }\end{array}$ & Acidic & $3-4$ & 4 & 4 & 4 & 4 & 4 & 4 \\
$\begin{array}{c}\text { Mordanted, } \\
\text { dyed and }\end{array}$ & Acidic & 4 & 5 & 5 & 5 & 5 & 5 & 5 \\
$\begin{array}{c}\text { Copper } \\
\text { sulphatetreated } \\
\text { Sample }\end{array}$ & Alkaline & $4-5$ & 5 & 5 & 5 & 5 & 5 & 5 \\
\hline
\end{tabular}

The above observation implies that, color fastness to perspiration for only turmeric dyed sample has been improved for mordanted and dyed sample. Color fastness to perspiration for mordanted, dyed and copper sulphate treated sample has been almost the same to mordanted and dyed sample but improved from only turmeric dyed sample.

\subsection{Effect of Color Fastness to Water on Different Dyeing Parameter}

Color fastness to water was observed by both change in color scale and staining in color scale. The result is shown in Table 4.

Table 4. Color fastness to water on change of dyeing parameters.

\begin{tabular}{|c|c|c|c|c|c|c|c|}
\hline \multirow{2}{*}{ Samples } & \multirow{2}{*}{$\begin{array}{c}\text { Change in } \\
\text { color }\end{array}$} & \multicolumn{6}{|c|}{ Staining in color } \\
\hline & & Di acetate & Cotton & Polyamide & Polyester & Acrylic & Wool \\
\hline Only dyed Sample & $2-3$ & 3 & $2-3$ & $2-3$ & 3 & 3 & $2-3$ \\
\hline $\begin{array}{l}\text { Mordanted and dyed } \\
\text { Sample }\end{array}$ & $4-5$ & 4 & 4 & $3-4$ & $4-5$ & 5 & 5 \\
\hline Mordanted, dyed and & & & & & & & \\
\hline $\begin{array}{l}\text { Copper sulphate } \\
\text { treated Sample }\end{array}$ & $4-5$ & $4-5$ & 4 & $3-4$ & 5 & 5 & 5 \\
\hline
\end{tabular}

The above observation implies that, color fastness to water for "only turmeric dyed sample" was not good enough (the range between fair to good). Color fastness to water for mordanted and dyed sample has been improved (the range between very good to excellent). Color fastness to water for "mordanted, dyed and copper sulphate treated sample" has been slightly improved than the previous one.

\subsection{Effect of Color Strength on Different Dyeing Parameters}

Table 5 describes the comparison of color strength value at different dyeing conditions. The only dyed value shows the higher value. Tamarind mordanted plus dyed sample shows 3.5 which is acceptable for making a shade and gives 
good fastness property as previously noted.

Table 5. Evaluation of color strength on different dyeing parameters.

\begin{tabular}{ccc}
\hline Sample & Wavelength $(\mathrm{nm})$ & K/S value \\
\hline Only Dyed & 430 & 6.4 \\
$\mathrm{CuSO}_{4}+$ Tamarind mordanted + Dyed & 430 & 3.4 \\
Tamarind mordanted + Dyed & 430 & 3.5 \\
\hline
\end{tabular}

\section{Conclusion}

Tamarind seed, as a by-product of tamarind pulp industries, basically is a distinctive underutilized material. The feasibility of tamarind seed coats extract as a natural mordant for dyeing silk fabric with turmeric powder dye via color measurement and color fastness testing was investigated in this study. The effect of mordanting on the color strength and fastness properties was studied in the course of the investigation. This study also investigated the optimal conditions of this dyeing process for getting good results by varying tannin concentration, time and temperature of dyeing. On the basis of the above study, authors got better results at $15 \mathrm{~g} / \mathrm{l}$ (owf) tannin (tamarind seed coat extracted) treated sample dyeing for $60 \mathrm{~min}$ at temperature $80^{\circ} \mathrm{C}$. Mordanting with tannin improves overall fastness properties and color strength value. Thus natural dye with tamarind mordanted natural mordant may serve as an eco-friendly alternative to their synthetic counterparts to make a greener life. There is hope that, natural coloring can be customized for rigorous approach functional parameters of synthetic dyestuffs and can be cost effective opportunities for the textile and clothing industry through systematic research.

\section{Suggestions for Future Work}

- In this experiment, tamarind seed coat was used to extract tanin, previous work has been carried on using amla fruit to extract tanin. Further works can be carried on using fruit, bark, stem, stock or other parts of different trees to extract tanin and use as mordant. In future, researchers may get more sources for tanin extraction.

- Here, water medium was used for extraction of tanin from tamarind seed coat form, but in future researchers may continue experiment using other media for mordant extraction like alkaline medium etc.

- Turmeric powder used here as sources of natural dye in combination with tamarind seed coat tanin. But, in the future, further experiments may be carried out by using other natural sources of dyes and possible to get better performance.

- To get better color fastness properties, the fabric can be treated with slightly acidic citric acid from natural sources like orange etc. As silk is a protein fiber made fabric, it may improve the color fastness properties especially wash fastness. 
These are some future work suggestions. But it is true that research is a never ending process. So, there are a lot more chances to modify and pursue advanced research work from here. We anticipate that our initiative will be advanced in the future and a lot more works will go on from our initiative.

\section{Acknowledgements}

The authors gratefully acknowledge physical testing and analytical laboratory of Department of Textile Engineering, Mawlana Bhashani Science and Technology University for technical support of this work.

\section{Conflicts of Interest}

The authors have declared no conflict of interest.

\section{Compliance with Ethics Requirements}

This article does not contain any studies with human or animal subjects performed by any of the authors.

\section{References}

[1] Balakrishnan, D.K., Thiyagarajan, S. and Balakrishnan, K. (2016) Extraction and Application of Eco- Friendly Natural Dye Obtained from Flower of Acacia eburnea (L.f.) Willd on Cotton Fabric. SOJ Materials Science \& Engineering, 4, 1-4. https://doi.org/10.15226/sojmse.2016.00137

[2] Singhee, D. and Samanta, P. (2018) Studies on Dyeing Process Variables for Application of Tesu (Butea monosperma) as Natural Dye on Silk Fabric. Journal of Natural Fibers, 16, 1098-1112. https://doi.org/10.1080/15440478.2018.1453430

[3] Asif, A.K.M.A.H. and Hasan, M.Z. (2018) Application of Nanotechnology in Modern Textiles: A Review. International Journal of Current Engineering and Technology, 8, 227-231. https://doi.org/10.14741/ijcet/v.8.2.5

[4] Asif, A.K.M.A.H. (2017) An Overview of Sustainability on Apparel Manufacturing Industry in Bangladesh. Science Journal of Energy Engineering, 5, 1-12. https://doi.org/10.11648/j.sjee.20170501.11

[5] Al-Fatimi, M., Wurster, M., Schröder, G. and Lindequist, U. (2007) Antioxidant, Antimicrobial and Cytotoxic Activities of Selected Medicinal Plants from Yemen. Journal of Ethnopharmacology, 111, 657-666. https://doi.org/10.1016/j.jep.2007.01.018

[6] Malešev, D. and Kuntić, V. (2007) Investigation of Metal Falvonoid Chelates and the Determination of Flavonoids via Matel-Flavonoid Complexing Reactions. Journal of the Serbian Chemical Society, 72, 921-939. https://doi.org/10.2298/JSC0710921M

[7] Cornard, J.P., Boudet, A.C. and Merlin, J.C. (2001) Complexes of Al (III) with 3'4'-Dihydroxy-Flavone: Characterization, Theoretical and Spectroscopic Study. Spectrochemica Acta Part A, 57, 591-602. https://doi.org/10.1016/S1386-1425(00)00412-1

[8] Chant, S.R. (1993) Fables. In: Heywood, V.H., Ed., Flowering Plants of the World, B.T. Batsford Ltd., London.

[9] Becker, H., Scher, J.M., Speakman, J. and Zapp, J. (2005) Bioactivity Guided Isola- 
tion of Antimicrobial Compounds from Lythrum salicaria. Fitoterapia, 76, 580-584. https://doi.org/10.1016/j.fitote.2005.04.011

[10] Vankar, P.S., Shanker, R., Dixit, S., Mahanta, D. and Tiwari, S.C. (2008) Sonicator Dyeing of Natural Polymers with Symplocos spicata by Metal Chelation. Fibers and Polymers, 9, 121-127. https://doi.org/10.1007/s12221-008-0020-6

[11] Feng, X.X., Zhang, L.L., Chen, J.Y. and Zhang, J.C. (2007) New Insights into Solar UV-Protective Properties of Natural Dye. Journal of Cleaner Production, 15, 366-372. https://doi.org/10.1016/j.jclepro.2005.11.003

[12] (1999) Colors to Dye for: Preparation of Natural Dyes. Journal of Chemical Education, 76, 1688A. https://doi.org/10.1021/ed076p1688A

[13] Almeida, M.M.B., de Sousa, P.H.M., Fonseca, M.L., Magalhães, C.E.C., Lopes, M.F.G. and de Lemos, T.L.G. (2009) Evaluation of Macro and Micro-Mineral Content in Tropical Fruits Cultivated in the Northeast of Brazil. Ciência e Technologia de Alimentos, 29, 581-586. https://doi.org/10.1590/S0101-20612009000300020

[14] Natarajan, S., Ramaelondran, E. and Suja, D. (1997) Growth of Some Urinary Crystals and Studies on Inhibitors and Promoters Part-2, X-Ray Studies and Inhibitory or Promotery Role of Some Substance. Crystal Research and Technology, 32, 553-559. https://doi.org/10.1002/crat.2170320409

[15] Mamun, M.A.A., Rahman, M., Asif, A.K.M.A.H. and Sarkar, P. (2014) Effect of Dyeing Parameters on Color Strength and Fastness Properties of Cotton Knitted Fabric Dyed with Direct Dyes. International Journal of Current Engineering and Technology, 4, 1068-1072.

[16] Li, W., Tang, Y., Zeng, Y., Tong, Z., Liang, D. and Cui, W. (2012) Adsorption Behavior of $\mathrm{Cr}(\mathrm{VI})$ Ions on Tannin-Immobilized Activated Clay. Chemical Engineering Journal, 193-194, 88-95. https://doi.org/10.1016/j.cej.2012.03.084

[17] Iqbal, M.S., Mamun, M.A.A., Siddiquee, M.A.B. and Asif, A.K.M.A.H. (2016) Effect of Finishing Machine Parameters on Dimensional Stability of Single Lacoste Cotton Knitted Fabric. Advances in Materials, 5, 35-43. https://doi.org/10.11648/j.am.20160505.12

[18] Russell, A. (1935) The Natural Tannins. Chemical Review, 17, 155-186. https://doi.org/10.1021/cr60057a002

[19] Singleton, V.L., Orthofer, R. and Lamuela-Raventos, R.M. (1999) Analysis of Total Phenols and Other Oxidation Substrates and Antioxidants by Means of Folin-Ciocalteau Reagent. Methods of Enzymology, 299, 152-178. https://doi.org/10.1016/S0076-6879(99)99017-1

[20] Siddiquee, M.A.B., Asif, A.K.M.A.H., Khan, R.H., Anwar, M.T., Islam, M.S. and Noushin, N. (2016) Study on the Effect of Dyeing and Finishing Parameters on Cotton Knitted Two Thread Fleece Fabric and 1x1 Rib Fabric. Science Research, 4, 7-10. https://doi.org/10.11648/j.sr.20160401.12

[21] Bechtold, T., Turcanu, A., Ganglberger, E. and Geissler, S. (2003) Natural Dyes in Modern Textile Dyehouse-How to Combine Experiences of Two Centuries to Meet Demands of the Future? Journal of Cleaner Production, 11, 499-509. https://doi.org/10.1016/S0959-6526(02)00077-X

[22] Dagar, J.C. (1995) Agroforestry Systems For The Andaman and Nicobar Islands. International Tree Crops Journal, 8, 107-128. https://doi.org/10.1080/01435698.1995.9752938

[23] Rahman, M., Asif, A.K.M.A.H., Siddiquee, M.A.B. and Rokonuzzaman, M. (2014) Effect of Shade Percentage on Various Properties of Cotton Knitted Fabric Dyed with Reactive Dyes. International Journal of Research in Engineering and Technol- 
ogy, 3, 339-343. https://doi.org/10.15623/ijret.2014.0302061

[24] De, M., De Krishna, A. and Baneerjee, A.B. (1999) Antimicrobial Screening of Some Indian Spices. Phytotheraphy Research, 13, 616-618. https://doi.org/10.1002/(SICI)1099-1573(199911)13:7<616::AID-PTR475>3.0.CO;2$\underline{\mathrm{V}}$

[25] Deepti, G., Sudhir, K.K. and Ankur, L. (2004) Antimicrobial Properties of Natural Dyes against Gram Negative Bacteria. Coloration Technology, 120, 167-171. https://doi.org/10.1111/j.1478-4408.2004.tb00224.x

[26] Maru, H., Nagashima, Y., Kanai, H. and Nishimatsu, T. (2017) Study on Fabric Character Triggering Fabric Appearance/Fabric Hand. Journal of Textile Engineering, 63, 141-148. https://doi.org/10.4188/jte.63.141

[27] Ahmed, S., Ahmad, M., Swami, B.L. and Ikram, S. (2016) A Review on Plants Extract Mediated Synthesis of Silver Nanoparticles for Antimicrobial Applications: A Green Expertise. Journal of Advanced Research, 7, 17-28. https://doi.org/10.1016/j.jare.2015.02.007

[28] Ajmal, M., Adeel, S., Azeem, M., Zuber, M., Akhtar, N. and Iqbal, N. (2014) Modulation of Pomegranate Peelcolourant Characteristics for Textile Dyeing Using High Energy Radiations. Industrial Crops and Products, 58, 188-193. https://doi.org/10.1016/j.indcrop.2014.04.026

[29] Ali, S., Hussain, T. and Nawaz, R. (2009) Optimization of Alkaline Extraction of Natural Dye from Henna Leaves and Its Dyeing on Cotton by Exhaust Method. Journal of Cleaner Production, 17, 61-66. https://doi.org/10.1016/j.jclepro.2008.03.002

[30] Khan, S.A., Ahmad, A., Khan, M.I., Yusuf, M., Shahid, M., Manzoor, N. and Mohammad, F. (2012) Antimicrobial Activity of Wool Yarn Dyed with Rheum Emodi (Indian Rhubarb). Dyes and Pigments, 95, 206-214. https://doi.org/10.1016/j.dyepig.2012.04.010

[31] Mansour, R., Ezzili, B. and Farouk, M. (2016) The Use of Response Surface Method to Optimize the Extraction of Natural Dye from Winery Waste in Textile Dyeing. The Journal of The Textile Institute, 108, 528-537. https://doi.org/10.1080/00405000.2016.1172821

[32] ISO 105-C04 (1987) Textiles-Tests for Color Fastness-Part C04: Color Fastness to Washing.

[33] ISO 105-E01 (2013) Textiles-Tests for Color Fastness-Part E01: Color Fastness to Water.

[34] ISO 105-X12 (2016) Textiles-Tests for Color Fastness-Part X12: Color Fastness to Rubbing.

[35] ISO 105-E04 (2013) Textiles-Tests for Color Fastness-Part E04: Color Fastness to Perspiration.

[36] https://sensing.konicaminolta.us/blog/identifying-color-differences-using-l-a-b-or-1 -c-h-coordinates 